78. Yewdell, J. W. \& Bennink, J. R. Immunodominance in major histocompatibility complex class I-restricted Tlymphocyte responses. Annu. Rev. Immunol. 17, 51-88 (1999).

79. Ulmer, J. B. et al. Heterologous protection against influenza by injection of DNA encoding a viral protein Science 259, 1745-1749 (1993).

80. Hanke, T. et al. Enhancement of MHC class I-restricted peptide-specific $\mathrm{T}$ cell induction by a DNA prime/MVA boost vaccination regime. Vaccine 16, 439-445 (1998).

81. Schneider, J. et al. Enhanced immunogenicity for CD8 $T$ cell induction and complete protective efficacy of malaria DNA vaccination by boosting with modified vaccinia virus Ankara. Nature Med. 4, 397-402 (1998)

82. Le, T. P. et al. Safety, tolerability and humoral immune responses after intramuscular administration of a malaria DNA vaccine to healthy adult volunteers. Vaccine $\mathbf{1 8}$ 1893-1901 (2000).

83. Wang, R. et al. Induction of antigen-specific cytotoxic T lymphocytes in humans by a malaria DNA vaccine. Science 282, 476-480 (1998).

84. MacGregor, R. R. et al. First human trial of a DNA-based vaccine for treatment of human immunodeficiency virus type 1 infection: safety and host response. J. Infect. Dis. 178, 92-100 (1998)

85. MacGregor, R. R., Boyer, J. D., Ciccarelli, R. B., Ginsberg, R. S. \& Weiner, D. B. Safety and immune responses to a DNA-based human immunodeficiency virus (HIV) type I env/rev vaccine in HIV-infected recipients: follow-up data. J. Infect. Dis. 181, 406 (2000).

86. Ugen, K. E. et al. DNA vaccination with HIV-1 expressing constructs elicits immune responses in humans. Vaccine 16, 1818-1821 (1998)

87. Boyer, J. D. et al. Vaccination of seronegative volunteers with a human immunodeficiency virus type 1 env/rev DNA vaccine induces antigen-specific proliferation and lymphocyte production of $\beta$-chemokines. J. Infect. Dis. 181, 476-483 (2000)

88. Calarota, S. et al. Cellular cytotoxic response induced by DNA vaccination in HIV-1-infected patients. Lancet 351 1320-1325 (1998)

89. Calarota, S. A. et al. Immune responses in asymptomatic HIV-1-infected patients after HIV-DNA immunization followed by highly active antiretroviral treatment.
for followed by highly active antiretrovira)
J. Immunol. 163, 2330-2338 (1999).

90. Yewdell, J. W. Bennink, J. R. Smith, G. L. \& Moss, B. Influenza A virus nucleoprotein is a major target antigen for cross-reactive anti-influenza A virus cytotoxic T lymphocytes. Proc. Natl Acad. Sci. USA 82 1785-1789 (1985).

91. Bennink, J. R., Yewdell, J. W., Smith, G. L., Moller, C. \& Moss, B. Recombinant vaccinia virus primes and stimulates influenza haemagglutinin-specific cytotoxic T cells. Nature 311, 578-579 (1984)

92. Clements-Mann, M. L. et al. Immune responses to human immunodeficiency virus (HIV) type 1 induced by canarypox expressing HIV-1MN gp120, HIV-1SF2 recombinant gp120, or both vaccines in seronegative adults. NIAID AIDS Vaccine Evaluation Group. J. Infect. Dis. 177, 1230-1246 (1998)

93. Egan, M. A. et al. Induction of human immunodeficiency virus type 1 (HIV-1)-specific cytolytic T lymphocyte responses in seronegative adults by a nonreplicating, hostrange-restricted canarypox vector (ALVAC) carrying the range-restricted canarypox vector (ALVAC) carrying the
HIV-1MN env gene. J. Infect. Dis. 171, 1623-1627 (1995).

94. Graham, B. S. et al. Vaccination of vaccinia-naive adults with human immunodeficiency virus type $1 \mathrm{gp} 160$ with human immunodeficiency virus type $1 \mathrm{gp} 160$
recombinant vaccinia virus in a blinded, controlled randomized clinical trial. The AIDS Vaccine Clinical Trials randomized clinical trial. The AIDS Vaccine Clin

95. Kantakamalakul, W. et al. Cytotoxic T lymphocyte responses to vaccinia virus antigens but not HIV-1 subtype E envelope protein seen in HIV-1 seronegative Thais. Asian Pac. J. Allergy Immunol. 19, 17-22 (2001).

96. Zagury, D. et al. A group specific anamnestic immune reaction against HIV-1 induced by a candidate vaccine against AIDS. Nature 332, 728-731 (1988).

97. Carruth, L. M. et al. An algorithm for evaluating human cytotoxic T lymphocyte responses to candidate AIDS vaccines. AIDS Res. Hum. Retroviruses 15, 1021-1034 (1999).

98. Girard, M., Habel, A. \& Chanel, C. New prospects for the development of a vaccine against human immunodeficiency virus type 1. An overview. C. R. Acad. Sci. III 322, 959-966 (1999)

99. Kent, S. J. et al. Enhanced T-cell immunogenicity and protective efficacy of a human immunodeficiency virus protective efficacy of a human immunodeficiency virus
type 1 vaccine regimen consisting of consecutive priming type 1 vaccine regimen consisting of consecutive priming
with DNA and boosting with recombinant fowlpox virus. with DNA and boosting with recombir
J. Virol. 72, 10180-10188 (1998).

100. Hel, Z. et al. Potentiation of simian immunodeficiency virus (SIV)-specific CD $4^{+}$and $C D 8^{+} T$ cell responses by a DNA-SIV and NYVAC-SIV prime/boost regimen. J. Immunol. 167, 7180-7191 (2001).
101. Mayr, A., Stickl, H., Muller, H. K., Danner, K. \& Singer, H. The small pox vaccination strain MVA: marker genetic structure, experience gained with the parenteral vaccination and behavior in organisms with a debilitated defence mechanism (author's transl.)]. Zentrallbl. Bakteriol. [B] 167, 375-390 (1978).

102. Stickl, H. et al. [MVA vaccination against smallpox: clinical tests with an attenuated live vaccinia virus strain (MVA) (author's transl)]. Dtsch. Med. Wochenschr. 99, 2386-2392 (1974).

103. Barouch, D. H. et al. Reduction of simian-human immunodeficiency virus $89.6 \mathrm{P}$ viremia in rhesus monkeys by recombinant modified vaccinia virus Ankara vaccination. J. Virol. 75, 5151-5158 (2001).

104. Cromwell, M. A. et al. Induction of mucosal homing virusspecific $\mathrm{CD}^{+} \mathrm{T}$ lymphocytes by attenuated simian immunodeficiency virus. J. Virol. 74, 8762-8766 (2000).

105. Gallimore, A. et al. Early suppression of SIV replication by $\mathrm{CD} 8^{+}$nef-specific cytotoxic T cells in vaccinated macaques. Nature Med. 1, 1167-1173 (1995).

106. Fuller, D. H et al Gene gun-based nucleic acid immunization alone or in combination with recombinant vaccinia vectors suppresses virus burden in rhesus macaques challenged with a heterologous SIV. Immunol. macaques challenged with a
Cell Biol. 75, 389-396 (1997).

107. Allen, T. M. et al. Induction of AIDS virus-specific CTL activity in fresh, unstimulated peripheral blood lymphocytes from rhesus macaques vaccinated with a DNA prime/modified vaccinia virus Ankara boost regimen. J. Immunol. 164, 4968-4978 (2000).

108. Kaul, R. et al. HIV-1-specific mucosal CD8+ lymphocyte responses in the cervix of HIV-1-resistant prostitutes in Nairobi. J. Immunol. 164, 1602-1611 (2000).

109. Kaul, R. et al. Late seroconversion in HIV-resistant Nairobi prostitutes despite pre-existing HIV-specific CD8 responses. J. Clin. Invest. 107, 341-349 (2001).

110. Rosenberg, E. S., LaRosa, L., Flynn, T., Robbins, G. \& Walker, B. D. Characterization of HIV-1-specific T-helper cells in acute and chronic infection. Immunol. Lett. 66 , 89-93 (1999).

111. Zhang, C., Cornette, J. L., Berzofsky, J. A. \& DeLisi, C. The organization of human leucocyte antigen class I epitopes in HIV genome products: implications for HIV evolution and vaccine design. Vaccine 15, 1291-1302 (1997).

112. Burrows, S. R. et al. T cell receptor repertoire for a viral epitope in humans is diversified by tolerance to a epitope in humans is diversified by tolerance to a
background major histocompatibility complex antigen. background major histocompatibility cor

113. Klenerman, P. et al. Cytotoxic T-cell activity antagonized by naturally occurring HIV-1 Gag variants. Nature $\mathbf{3 6 9}$, 403-407 (1994).

114. Reid, S. W. et al. Antagonist HIV-1 Gag peptides induce structural changes in HLA B8. J. Exp. Med. 184, 2279-2286 (1996).

115. Klenerman, P. \& Zinkernagel, R. M. Original antigenic sin impairs cytotoxic $T$ lymphocyte responses to viruses bearing variant epitopes. Nature 394, 482-485 (1998).
116. Mortara, L. et al. Selection of virus variants and emergence of virus escape mutants after immunization with an epitope vaccine. J. Virol. 72, 1403-1410 (1998).

117. Price, D. A. et al. Positive selection of HIV-1 cytotoxic T lymphocyte escape variants during primary infectio Proc. Natl Acad. Sci. USA 94, 1890-1895 (1997).

118. Kelleher, A. D. et al. Clustered mutations in HIV-1 gag are consistently required for escape from HLA-B27-restricted CTL responses. J. Exp. Med. 193, 375-386 (2001).

119. Korber, B. et al. Evolutionary and immunological implications of contemporary HIV-1 variation. Br. Med. Bull. 58, 19-42 (2001).

120. Goulder, P. J. et al. Evolution and transmission of stable CTL escape mutations in HIV infection. Nature $\mathbf{4 1 2}$ 334-338 (2001).

121. Hsu, S. C. et al. Protective cytotoxic T lymphocyte responses against paramyxoviruses induced by epitopebased DNA vaccines: involvement of IFN- $\gamma$. Int. Immunol. 10, 1441-1447 (1998).

122. Kulkarni A. B Connors, M. Firestone, C. Y Morse, H. C. III \& Murphy, B. R. The cytolytic activity of pulmonary CD ${ }^{+}$ lymphocytes, induced by infection with a vaccinia virus recombinant expressing the M2 protein of respiratory syncytial virus (RSV), correlates with resistance to RSV infection in mice. J. Virol. 67, 1044-1049 (1993).

123. Fu, T. M., Friedman, A., Ulmer, J. B., Liu, M. A. \& Donnelly, J. J. Protective cellular immunity: cytotoxic T-lymphocyte responses against dominant and recessive epitopes of influenza virus nucleoprotein induced by DNA immunization. J. Virol. 71, 2715-2721 (1997)

124. Rodriguez, F., Zhang, J. \& Whitton, J. L. DNA immunization: ubiquitination of a viral protein enhances cytotoxic T-lymphocyte induction and antiviral protection but abrogates antibody induction. J. Virol. 71, 8497-8503 (1997)

125. Seth, A. et al. Immunization with a modified vaccinia virus expressing simian immunodeficiency virus (SIV) Gag-Pol primes for an anamnestic Gag-specific cytotoxic T-lymphocyte response and is associated with reduction of viremia after SIV challenge. J. Virol. 74, 2502-2509 (2000).

126. Belyakov, I. M. et al. Mucosal AIDS vaccine reduces disease and viral load in gut reservoir and blood after mucosal infection of macaques. Nature Med. 7 . 1320-1326 (2001)

\section{(2) Online links}

\section{DATABASES}

The following terms in this article are linked online to: LocusLink: http://www ncbi.nlm nih gov/Locus ink

CCR5 | CD4 | CD8 | CXCR4 | |FN- $\alpha$ | |FN- $\gamma$ | ||-2 | ||-12 | MIP-1

\section{FURTHER INFORMATION}

The International AIDS Vaccine Initiative: http://www.iavi.org

Access to this interactive links box is free online

SCIENCE AND SOCIETY - VACCINES

\title{
Ethical issues for vaccines and immunization
}

\section{Jeffrey B. Ulmer and Margaret A. Liu}

Vaccination is the only type of medical intervention that has eliminated a disease successfully. However, both in countries with high immunization rates and in countries that are too impoverished to protect their citizens, many dilemmas and controversies surround immunization. This article describes some of the ethical issues involved, and presents some challenges and concepts for the global community.
Vaccines stand out as being among the most efficacious and cost-effective of global medical interventions ${ }^{1}$ (BOX 1). Vaccines have saved millions of lives, prevented significant morbidity and suffering, and even eradicated a disease. This last accomplishment, the eradication of smallpox, highlights what can be achieved by vaccination. However, unfortunately, the inequalities in the distribution and use of vaccines are also striking. If vaccines 


\section{Box 1 | The economic benefits and cost-effectiveness of vaccines}

The statistics for the eradication of smallpox illustrate the benefits and economics of vaccines and disease eradication. The eradication of smallpox has probably saved 40 million lives over the past two decades ${ }^{6}$, at a cost of US $\$ 25$ million per year during the eradication campaign. The equivalent of US $\$ 275$ million is saved annually in terms of quarantine and treatment because of the eradication of smallpox ${ }^{3}$.

The eradication of polio is also within reach. Between 1988 and 2000, coordinated public-health efforts, with a large contribution from Rotary International, have decreased the number of polio cases from approximately 350,000 to 3,500 per annum ${ }^{6}$. The potential future cost savings of polio eradication have been estimated at US $\$ 1.5$ billion per year ${ }^{6}$, although the actual savings will probably be less than this owing to the need to continue immunization after eradication.

The cost of immunizing a child with the six core vaccines that are recommended by the Expanded Program on Immunization (tuberculosis, measles, diphtheria, tetanus, pertussis and polio) is US $\$ 17$ (REF. 6). Of this amount, only a few dollars are for the cost of the vaccines, with the rest paying, for example, for personnel and transportation of the vaccine (including refrigeration).

The benefits of vaccines are obvious in terms of the lives that are saved and the morbidity that is prevented or reduced, but the economic benefits extend beyond the benefits to the individuals that are protected. The economic benefits of immunization campaigns include savings in health-care costs for the treatment of illness and quarantine, the economic productivity of having a healthy workforce (or of not having parents removed from the workforce to care for an ill child) and coincident benefits that result from the immunization programme (such as an improved health-care infrastructure).

can be deployed so successfully worldwide that a disease can be eliminated, why do millions of children still die each year from other vaccine-preventable diseases? From ethical and humanitarian perspectives, this should be unacceptable. However, despite the medical evidence of the benefits of vaccines, both immunization itself as a goal, as well as the actual efforts for global immunization, are often debated and criticized. So, the ethics of whether, and how, to vaccinate all of the world's population are much more complex than it would seem at first glance. Some of these issues will be examined and a call for action raised in this article.

\section{Current state of immunization rates}

At present, in industrialized countries such as the United States, infants routinely ( $\sim 80-95 \%$ coverage) receive vaccines against diphtheria, pertussis (whooping cough), tetanus, measles, mumps, rubella, polio, Haemophilus influenzae type b, hepatitis B, varicella, pneumococcus and, often, hepatitis A. The efficacy of these vaccines and the success of routine immunizations are such that in the United States, for example, the morbidity from previously routine childhood diseases has been reduced by $90-100 \%$ since the introduction of standard immunization ${ }^{2}$ (TABLE 1). In developed countries, the near disappearance of these diseases from normal childhood has removed much of the fear of the illnesses that they cause. The result is that the consequences of not vaccinating against these diseases are sometimes not fully appreciated by the public.
In developing countries, one in every four children born annually will not be vaccinated ${ }^{3}$. In many of the impoverished countries in which these children reside, the concomitant lack of health care, inadequate nutrition ${ }^{4}$, higher prevalence of disease, decreased hygiene and over-crowding conspire to increase the incidence of, as well as the morbidity and mortality from, both vaccine-preventable and other infectious diseases. Six children die every minute as a result of infectious diseases that could be prevented by existing vaccines, and for measles alone, nearly one million children die each year ${ }^{3}$. So, each day, 4,000-8,000 people ${ }^{3}$, mainly children, die from vaccinepreventable diseases (TABLE 2).

Various efforts to increase global immunization rates have protected many children successfully. For example, in 1974, before the Expanded Program on Immunization (EPI) was established, an estimated 8 million children died each year from measles 5 . Since then, the EPI has targeted six diseases: tuberculosis, measles, diphtheria, tetanus, pertussis and polio (FIG. 1). By 1980, the incidence of measles had been reduced by $\sim 50 \%$ (FIG. 2). In that year, the World Summit for Children set a goal of $80 \%$ coverage for these six basic immunizations to be achieved by 1990 . Laudably, those efforts succeeded in raising global immunization rates from less than $10 \%$ to almost $80 \%$ in that decade ${ }^{6}$, with a concomitant reduction in disease burden (for example, see FIG. 2). But, a combination of complacency, competition for health-care resources with other diseases (such as HIV) and other factors, such as an inadequate and ageing health-care infrastructure, resulted in a subsequent plateau ${ }^{5}$ or decline in average immunization rates in the developing world ${ }^{6}$. This trend is worrying because of what it represents in terms of the commitment and sustainability of immunization programmes. Maintenance of a high level of coverage for immunization is crucial - unless a certain minimum percentage of the population is immune, the benefits of herd immunity (when sufficient people are immune such that a pathogen cannot easily persist and spread in a population) will not be achieved.

\section{Ethics of immunization and vaccines}

The economic and human benefits of vaccination are clear for many vaccines. But, economic and political realities, along with philosophical questions, raise certain ethical issues concerning the use and distribution of vaccines $^{7}$. What are the rights of individuals in deciding about vaccination versus the rights of, and risks to, society? Should different standards for the efficacy and safety of a particular vaccine be set for different populations for which the risk:benefit ratio might be different? How should priorities be set for different areas

\begin{tabular}{|c|c|c|c|}
\hline \multirow[t]{2}{*}{ Disease } & \multicolumn{3}{|c|}{ Number of cases } \\
\hline & Maximum & 1997 & $\%$ change \\
\hline Diphtheria & 206,939 & 4 & 99.99 \\
\hline Measles & 894,134 & 138 & 99.98 \\
\hline Mumps & 152,209 & 683 & 99.55 \\
\hline Pertussis (whooping cough) & 265,269 & 6,564 & 97.52 \\
\hline Polio (paralytic) & 21,269 & 0 & 100.00 \\
\hline Rubella & 57,686 & 181 & 99.69 \\
\hline Congenital rubella syndrome & $20,000^{*}$ & 5 & 99.98 \\
\hline Tetanus & $1,560^{\ddagger}$ & 50 & 96.79 \\
\hline Influenza ( $<5$ years) & $20,000^{*}$ & 165 & 99.18 \\
\hline
\end{tabular}

Data taken from REF. 5. ${ }^{*}$ estimated; ${ }^{\ddagger}$ mortality. 
between and within countries? Which regulatory bodies have the right to make decisions at the individual or national level? Although few would argue against the responsibility of developed nations to help poorer countries and peoples to develop and use the necessary vaccines, what are the precise responsibilities of both developed and developing countries? Here, we examine several of these issues to highlight the complexities of the ethics of vaccine development and use.

Whose choice is it? During the period when polio epidemics struck terror into the hearts of the population, the public clamoured for, supported the development of (for example, The March of Dimes in the United States, a national public compaign to raise donations to fund the research and development of polio vaccines) and welcomed a vaccine against polio. The live attenuated vaccine made possible a global mass-immunization campaign; on a single day of the various National Immunization Days, 83-147 million children were immunized ${ }^{8,6}$. Now, at a time when wild-type polio has been eliminated from the Western Hemisphere and nearly eradicated globally, the only cases of polio in the Western Hemisphere are caused by reversion mutants of the live-attenuated vaccine strain of the virus. For society as a whole, the total elimination of polio seems the obvious and correct path. But, as the probability of an individual being exposed to the virus decreases, and as the devastation of the historic polio epidemics fades in our memories, the rare cases of disease due to reversion of the vaccine itself become more prominent. The benefit of immunization for any given individual decreases (due to a lower probability of contracting the disease), whereas the perception of risk might increase ${ }^{9}$. So, what is best for the individual might be seen as potentially different from what will benefit

\begin{tabular}{ll}
\hline \multicolumn{2}{l}{ Table 2 | Global vaccine-preventable deaths through infant immunization } \\
\hline Disease & Number of preventable annual deaths \\
\hline Hepatitis B & 900,000 \\
\hline Measles & 888,000 \\
\hline Tetanus (including 215,000 neonatal deaths) & 410,000 \\
\hline Haemophilus influenzae type b (Hib) & 400,000 \\
\hline Pertussis (whooping cough) & 346,000 \\
\hline Yellow fever & 30,000 \\
\hline Diphtheria & 5,000 \\
\hline Polio & 720 \\
\hline Total & $\mathbf{2 , 9 7 9 , 7 2 0}$ \\
\hline
\end{tabular}

Data taken from the World Health Organization (WHO) World Health Report 1999 and the WHO Department of Vaccines and Biologicals. society as a whole. However, it has only been through the participation of hundreds of millions of individuals in vaccination programmmes that unimmunized individuals have the luxury of an altered risk:benefit ratio. Interestingly, in 1980, the year that smallpox was officially declared to be eradicated, prominent individuals in the international healthplanning community were critical of the smallpox campaign. They felt that the approach of 'top-down' (mandated and orchestrated by global bodies) programmes was wrong and contrary to more-localized, primary health care $^{10,11}$. Even this pre-eminent example of the beneficial power of immunization was not without controversy.

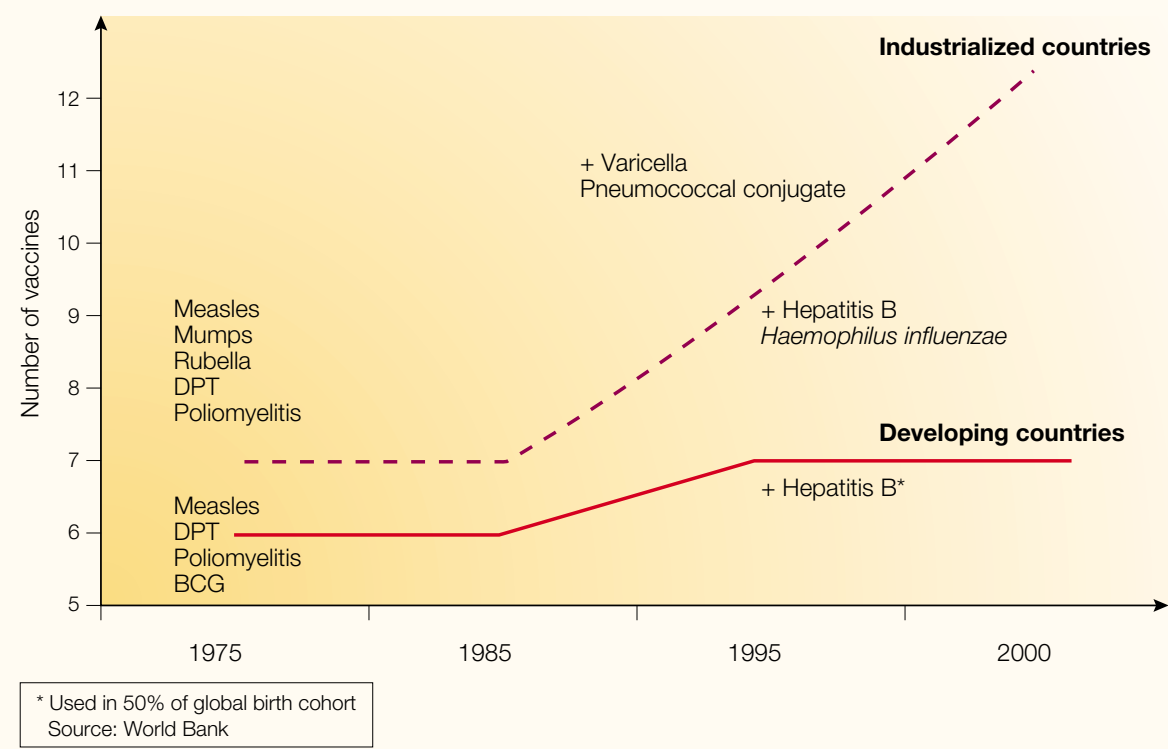

Figure 1 | Number of children's vaccines used routinely in developing and industrialized countries. As shown, the number of vaccines ( $y$ axis) that are given to children has risen steadily since 1985 in industrialized countries, but not in developing countries. DPT is a combination vaccine against three separate pathogens: diphtheria (D), pertussis $(P)$ and tetanus $(T)$. BCG is the Mycobacterium bovis bacillus Calmètte-Guerin vaccine against tuberculosis. The loss of life due to lack of infant immunization in developing countries is due to the smaller number of vaccines that are routinely used, as well as to lower immunization rates. Reproduced, with permission, from the World Health Organization ${ }^{6}$.

In the same manner, other vaccines have become victims of their own success. As diseases disappear from the general population after successful vaccination campaigns, the real risk of an individual contracting the disease decreases and the perception of the seriousness of the disease, even if contracted, is reduced. Concomitantly, concerns about the real or imagined adverse effects of the vaccines increase. As a result, individuals might disagree with government mandates for population-wide vaccination. For example, before the introduction of a vaccine against pertussis, there were approximately 2 million cases annually in the United States. In Great Britain, in the mid-1970s, some adverse reactions to the vaccine were widely publicized, and immunization rates declined from $80-90 \%$ to $30 \%$. As a consequence, the population was vulnerable to two subsequent severe outbreaks of whooping cough, which resulted in more than 120,000 recorded instances of disease, hundreds of cases of serious complications and 28 deaths $s^{12}$. More recently, heightened fears of the perceived adverse effects of other vaccines (such as measles and hepatitis B), even if unproven, have had an impact on immunization rates and the incidence of disease $e^{6,13-15}$. A greater awareness of the consequences of failure to vaccinate, through better education, might be the best tool to combat this problem ${ }^{16}$. 


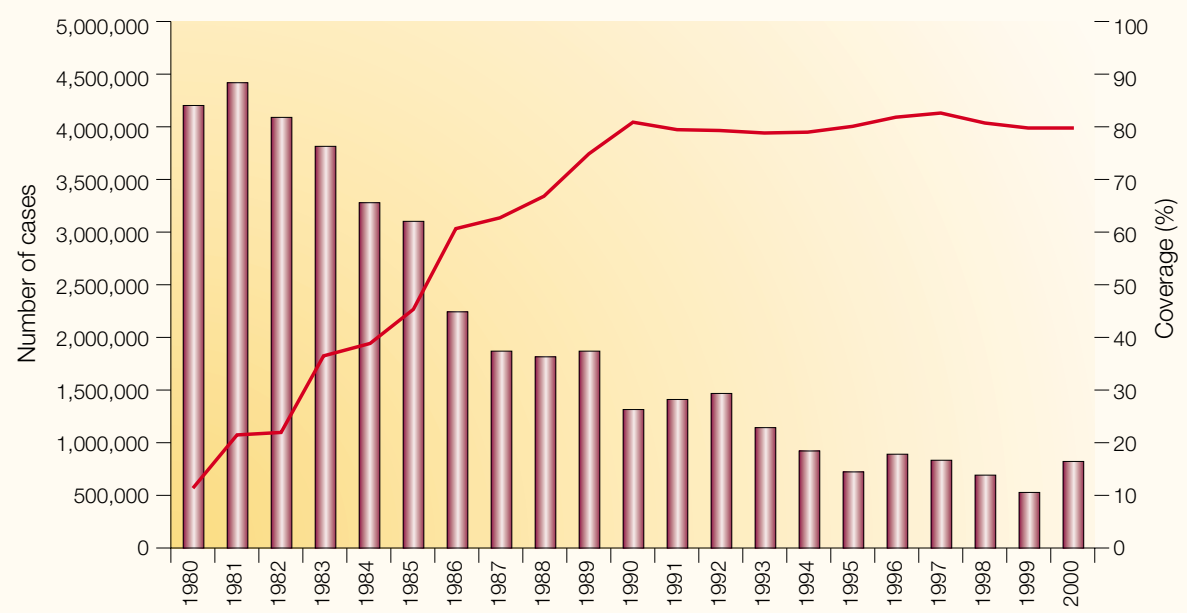

Number of cases

Immunization coverage

Figure 2 | Measles global annual reported incidence and immunization coverage, 1980-2000 The global incidence of measles has declined as immunization coverage has increased. The level of immunization coverage plateaued in the 1990s, leaving a significant number of cases of measles still occurring each year. Reproduced, with permission, from the World Health Organization ${ }^{22}$

Poverty and priorities. In wealthier countries, the ethical issues that surround vaccination tend to focus on the rights of individuals versus government or society. In poorer countries, the fundamental issue is the lack of access to basic necessities for health, such as adequate nutrition, clean water, medicines or vaccines. Although poverty is clearly the main cause of these deficiencies, other factors contribute, such as the low priority given to health and preventive measures, the disenfranchisement and lack of political and economic power of the people most affected (children and women), corruption and regional warfare.

In the year 2000 , only $10 \%$ of global medical-research funds were directed towards the $90 \%$ of diseases that affect the world's poorest people $^{6}$. It would seem obvious from the economic benefits that prevention of disease (and health in general) should be a priority for poor countries. It would seem equally obvious that helping to ensure such health should be a high priority for wealthy nations, even if simply to protect their own populations. Not only can newly emerging diseases spread rapidly across the globe, but pathogens eliminated from one population can be 'reimported' (or new strains introduced) by travellers or immigrants $s^{17}$.

At present, only about $1 \%$ of contributions to overseas development are directed towards immunizations $^{6}$. The hurdle is not simply the purchase price or availability of vaccines, but for many poor countries, there is a lack of infrastructure for health care in general, and vaccine delivery specifically. The needs are so great and so widespread, both geographically and technologically, that assigning priority is difficult. This prioritization is considered by some to be an ethical issue, but in reality, it might be simply that the pie is not sufficiently large, rather than that the pie should be sliced differently. The trade-off of protecting children now from disease versus an emphasis on the development of new vaccines to protect children in the future is not a debate that can be resolved even by Solomonic wisdom. Neither trade-off is ethically defensible, and the world should, instead, work constructively to increase the resources devoted to health, nutrition, prevention and specifically immunization, to make vaccines available to all people as required. But, how is this to be accomplished?

'Trickle-down' or simultaneous introduction. A marked effort is required to introduce vaccines into all necessary areas of the globe in a more timely fashion. The average time lag between licensing of a new vaccine for industrialized countries and its use in less developed countries is $10-20$ years $^{6}$. There are many reasons for this, including the lack of manufacturing capability for vaccines that require new technology in their production, return on investment and the cost of manufacturing newer technology-based vaccines. For example, when the recombinant hepatitis $B$ virus vaccine was first introduced, there was not sufficient capacity worldwide for its production. Moreover, the cost of manufacturing such a 'high-tech' vaccine put it beyond the reach of the existing purchasing programmes at the time. Although the technology that supports recombinant protein vaccines is now available worldwide, it took time and effort to develop that capacity, even in developed countries.

People are created equal, but different

The simultaneous introduction of vaccines into developed and developing countries is an important goal. However, this is easier said than done. In addition to the issues of availability and economics, it cannot be assumed that disease burden, strain prevalence, vaccine efficacy and effectiveness (how well a vaccine works in clinical trials and real-world settings, respectively), immunization schedules or risk:benefit ratio will be standard or will justify the use of a vaccine in all areas. Differences in genotype and health status of individuals could affect how their immune system responds to a given immune stimulus. Environmental influences on the immune system (for example, indigenous parasitic infections that affect the predominant cytokine-secretion profile of helper $\mathrm{T}$ cells, or bacterial infections that facilitate or hinder immunity against closely related pathogens) might affect the immunological outcome of a particular type of vaccine.

Just as a vaccine that works in one population might not be as effective in another population, so might adverse effects of a vaccine be specific to one population. Hence, a vaccine company might be reluctant to simultaneously test a vaccine in two populations, for fear that an adverse effect in one population (due to genetic, nutritional or other health factors, or limitations of the infrastructure for vaccine delivery) would halt the development of a vaccine that could be both useful and commercially viable in another population. More importantly, the higher background rates of morbidity and mortality in certain developing countries might cause problems when presenting vaccines for licensure in more developed countries.

A counter-example to illustrate why vaccines might need to be tested simultaneously in developed and developing countries is provided by a rotavirus vaccine. Rotavirus is a major cause of diarrhoea in infants. In the United States, 20 children die each year from rotavirus infection, and worldwide, the virus kills 600,000 children under the age of five annually ${ }^{18}$. In 1998, a new rotavirus vaccine was licensed in the United States. But by 1999, reports emerged from American clinics of the occurrence, after immunization, of a small number of cases of intestinal intussusception 
- a 'telescoping' of the small intestine that often requires emergency surgery ${ }^{18}$. The number of cases was small, and the aetiological link has been debated, but the vaccine was withdrawn from the market. Clinical trials that were testing the vaccine in developing countries were stopped. So, we do not yet know whether the vaccine would have been effective or caused side effects in children from developing countries, for whom the risk:benefit ratio might well be quite different. More than half a million children continue to die each year due to rotavirus infection (although it is hoped that other rotavirus vaccines that are under development will be approved for use). The issue of how to speed up vaccine deployment for developing countries and how to develop vaccines that specifically address the needs of those countries should not be oversimplified. Different vaccines (for example, for different virus strains) might be required to prevent the same disease in different parts of the world. The needs of people in developing countries must be specifically, rapidly and directly addressed to develop appropriate vaccines. To make this happen in a timely manner, more thought and effort is required at early stages of vaccine development. But, by whom and at whose expense?

\section{A farewell to arms}

In the face of the unacceptable and gaping inequalities in access to vaccines, the temptation has been to 'point the finger' at various countries or segments of society. A chief target for many of these denouncements has been large vaccine manufacturers, as well as the people and governments of their home countries. It has been easy to stir up indignation, although a thoughtful evaluation of the real contributions, roles and responsibilities of all parties has been more productive (BOX 2). The cries for companies to lower the prices of their vaccines has reinforced the unwarranted notion that vaccines should be inexpensive - an idea that perpetuates the vicious cycle of the low valuation of health care, prevention and children's lives. Obviously, low cost might be an important means of increasing access to vaccines, but the fundamental problem is the low priority given to children, health and prevention.

Most vaccines that are in use today were developed fully and are manufactured by industry, rather than the public sector. Commercial companies have responsibilities to their shareholders and are driven by profits. But, it is these profits that have enabled the companies to take the huge economic risks that are required for the long process of discovery, research and development of vaccines.

\section{Box 2 | Potential mechanisms to achieve equity in health}

The unequal access to existing vaccines and the relative lack of effort being applied to develop and produce vaccines for diseases that predominate in developing countries is part of the larger problem of extreme poverty in many nations. Although the roots and other manifestations of poverty must also be addressed, as Jorge Jiminez of the World Health Organization has said, "Health is seen more and more as preceeding development and not only as a consequence of wealth" ${ }^{20}$. Rather than relying on governments or international bodies as the sole means to address these problems, new models of public-private partnerships (PPPs) have arisen.

The fundamental idea of a PPP is to bring together entities from both the public sector (government or intergovernmental agencies) and the private sector (for example, industries, such as vaccine companies) to address a particular need, with each partner undertaking specific activities on the basis of their particular expertise and capacity.

Participation by industry might be in the form of donating a product, or applying research and development expertise to diseases (or types of health intervention) for which the market alone would not provide sufficient incentive. The motivation of the pharmaceutical industry might range from pure philanthropy (global citizenship and garnering goodwill) to economies of scale (if the product has a market elsewhere that will allow for higher prices to offset the lower prices in developing countries) ${ }^{21}$.

Recent PPPs have been established to tackle the challenges of developing and producing vaccines for diseases such as HIV and malaria. The input of effort or intellectual property from a 'for-profit' company and the potential loss due to 'opportunity costs' (that is, the possible revenue from a highly recompensed product if the effort had been directed towards that product rather than a vaccine for a developing country) can be strong disincentives for companies to participate in PPPs. Another approach that might become increasingly useful is the provision of early access to new vaccines and technologies for developing countries by the transfer of technology from a pharmaceutical company in an industrialized country to a local manufacturer in a developing country. Key roles for governmental and intergovernmental agencies include the regulation of products, and testing and manufacturing processes, and the prevention of reflow of products produced for lower pricing in developing countries into countries in which companies anticipate higher pricing to recoup the costs of development and make profits for reinvestment in future products.

If all economic incentive were removed, or made too small, even fewer companies would bother to make vaccines ${ }^{19}$, and, instead, would concentrate solely on therapeutic agents, because people will pay more for drugs that treat, rather than prevent, disease.

So, companies should not be expected to be philanthropic, although they should be expected to be generous global citizens. Indeed, industry-driven scientific and technological advances have had an important impact on improving global health. Combination vaccines - whereby several vaccines can be given with a single injection - were developed in part for the market advantage that they would provide but have been an important tool for increasing global vaccination rates. In addition, industry and academia are both contributing to the continuing development of vaccines that do not require refrigeration or needles and can be given orally or nasally — a true 'farewell to arms'.

In most walks of life, philanthropy usually comes as a consequence of success, and the same is true for medicines. So, the profitdriven priorities of vaccine companies are not unethical per se; rather, they are not driven primarily by ethical concerns, and the challenge is how to increase the efforts of industry that are directed at improving health on a global basis. The fact that only $1 \%$ of pharmaceuticals that reached the market-place between 1975 and 1997 were approved specifically for diseases of the developing world ${ }^{6}$ shows that, as a society, we need to re-evaluate our priorities and our paradigms, not that the economic model of financial incentive driving technical advances is wrong.

\section{The challenge}

We should challenge each economic sector, population and government to appropriately fulfil its responsibility to fellow humans or its own citizens; in other words, they should treat all of the world's children as their own, rather than denouncing particular groups as causing these inequities. Further support must be given rapidly to those whose efforts will result in vaccines that are better tailored for developing countries, both in terms of the disease focus and the development of technologies that will facilitate vaccine access and sustainability. New paradigms, including novel public-private partnerships (BOX 2) and alliances that are designed to engage local governments and 


\section{PER S PECTIVES}

manufacturers at early stages of research and development, are required. In this way, each group can contribute what they do best to the common goals of improving access to existing vaccines, developing new vaccines and technologies for existing diseases (such as HIV and malaria), and ensuring that increases in immunization rates are sustainable. Perhaps most difficult of all will be to change the mindset of people all over the globe. We need to place a higher priority on health and disease prevention, and above all, to value the lives of all people, no matter where they live - even if they are impoverished and powerless.

Jeffrey B. Ulmer is at Vaccines Research, Chiron Corporation, 4560 Horton Street, Emeryville, California 94608, USA.

Margaret A. Liu is at Transgene, 11 rue de Molshelm, 67082 Strasbourg Cedex, France. Correspondence to M. A. L. e-mail:liu@transgene.fr

DOI: $10.1038 /$ nri780

1. Ten great public health achievements - United States, 1900-1999. MMWR Morb. Mortal. Wkly Rep. 48, 241-243 (1999).

2. Impact of vaccines universally recommended for children - United States, 1990-1998. MMWR Morb. Mortal. Wkly Rep. 48, 243-248 (1999).

3. Global Alliance for Vaccines and Immunizations. Global immunization challenges [online], $<\mathrm{http}$ ///www.vaccinealliance.org/reference/globalimmcha llenges.html>

4. Rice, A. L., Sacco, L., Hyder, A., \& Black, R. E. Malnutrition as an underlying cause of childhood deaths associated with infectious diseases in developing countries. Bull. World Health Organ. 78, 1207-1221 (2000).

5. Hinman, A. Eradication of vaccine-preventable diseases. Annu. Rev. Public Health 20, 211-229 (1999).

6. World Health Organization. State of the World's Vaccine and Immunizations (in the press)

7. Feudtner, C. \& Marcuse, E. K. Ethics and immunization policy: promoting dialogue to sustain consensus. Pediatrics 107, 1158-1164 (2001).

8. Foege, W. in New Generation Vaccines (eds Levin, M., Woodrow, G., Kaper, J. \& Cobon, G.) 97 (Marcel Dekker, New York, 1997).

9. Wilson, C. B. \& Marcuse, E. K. Vaccine safety-vaccine benefits: science and the public's percepion. Nature Rev. Immunol. 1, 160-165 (2001).

10. Henderson, D. A. Eradication: lessons from the past. Bull. World Health Organ. 76,17-21 (1998).

11. Henderson, D. A. Primary health care as a practical means for measles control. Rev. Infect. Dis. 5, 606-607 (1983)

12. Ada, G. in New Generation Vaccines 2 nd edn (eds Levine, M. et al.) 13-24 (Marcel Dekker, New York, 1997).

13. Wakefield, A. et al. lleal-lymphoid-nodular hyperplasia non-specific colitis and pervasive developmental disorder in children. Lancet 351, 637-641 (1998).

14. Birmingham, K. UK immunization highs and lows. Nature Med. 7, 135 (2001).

15. Duffell, E. Attitudes of parents towards measles and immunisation after a measles outbreak in an anthroposophical community. J. Epidemiol. Community Health 55, 685-686 (2001).

16. Bazin, $H$. The ethics of vaccine usage in society: lessons from the past. Curr. Opin. Immunol. 13, 505-510 from the

17. Hinman, A. Eradication of vaccine-preventable diseases. Annu. Rev. Public Health 20, 211-229 (1999).
18. Instussusception among recipients of rotavirus vaccineUnited States, 1998-1999. MMWR Morb. Mortal. Wkly Rep. 48, 577-581 (1999).

19. Wilde, H. What are today's orphaned vaccines? Clin. Infect. Dis. 33, 648-650 (2001).

20. Jimenez, J. Vaccines - a wonderful tool for equity in health. Vaccine 19, 2201-2205 (2001).

21. Vandermissen, W. WHO expectation and industry goals. Vaccine 19, 1611-1615 (2001).

22. Department of Vaccines and Biologicals. WHO VaccinePreventable Diseases: Monitoring System 2001 Global Summary (World Health Organization, Geneva, 2001) <http://www.who.int/vaccinesdocuments/GlobalSummary/GlobalSummary.pdf>

Acknowledgements

We would like to thank C. Wiley and, in particular, R. Ingrum for their assistance.

\section{(9) Online links}

\section{FURTHER INFORMATION}

Public-private partnerships:

Global Polio Eradication Initiative: http://wnw.

polioeradication.org/

Global Program to Eliminate Lymphatic Filariasis: http://

www. filariasis.org/index.shtm

International AIDS Vaccine Initiative: http://www.iavi.org/ Mectizan Donation Program: http://65.208.79.90/MDP/

Medicines for Malaria Venture: http://www.mmv.org/

pages/page_main.htm

The Global Alliance for TB Drug Development: http://www tballiance.org/

Governmental and professional groups:

Global Alliance for Vaccines \& Immunization: http://www. vaccinealliance.org

National Network for Immunization information: http://www. immunizationinfo.org

World Health Organization: http://www.who.int/home-page/ Access to this interactive links box is free online. 